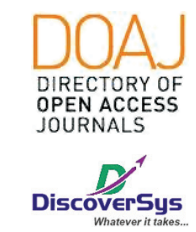

Published by DiscoverSys

\title{
The characteristics of neonatal sepsis in Low Birth Weight (LBW) infants at Sanglah General Hospital, Bali, Indonesia
}

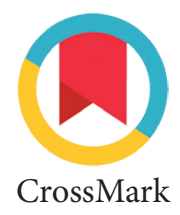

\author{
Novita Purnamasari Assa, ${ }^{1 *}$ I Wayan Dharma Artana, ${ }^{1}$ I Made Kardana, ${ }^{1}$ \\ Putu Junara Putra, ${ }^{1}$ Made Sukmawati ${ }^{1}$
}

\section{ABSTRACTS}

\begin{abstract}
Backgrounds: Neonatal sepsis is a significant cause of mortality and long-term morbidity. The preterm infant has high-risk sepsis and its sequelae. Low birth weight infants were more susceptible to sepsis. Initial infections in neonates may not be identified due to non-specific symptoms and sign with the limited laboratory criteria. This study aims to describe the characteristics of neonatal sepsis in low birth weight infants in the neonatology intensive care unit of Sanglah Hospital.

Methods: A retrospective cross-sectional study was conducted among 168 infants aged zero to 28 days with birth weights $<2,500$ grams from May 2017 - April 2018 at Sanglah General Hospital, Bali, Indonesia using a purposive sampling technique. The inclusion criteria were sepsis infants who were hospitalized in neonatology care rooms during the study period at Sanglah General Hospital. Variables assessed in this study were sex, location and mode of delivery, birth weight, gestational age, number of parity, length of stay, the onset of sepsis, as well as the outcome. Data were analysed using SPSS version 17 for Windows.
\end{abstract}

Results: The mortality rate of sepsis in low birth weight infants was $29.8 \%$. Most of the subjects were male (53\%), location of delivery at Sanglah Hospital (60.7\%), born spontaneously (51.2\%), birth weight were $1500-2499$ grams $(58,3 \%)$ and the most gestational ages were 3236 weeks (44,6\%). Early-onset neonatal sepsis (EONS) dominates patients with neonatal sepsis, with a mean length of stay was $23.27 \pm 20.32$ days. The major infection risk factor was premature rupture membrane (PRM) $>24$ hours (14.9\%), and minor infection risk factor was gestational age $<37$ weeks (78\%), very low birth weight (44.6\%) and asphyxia (41.1\%). The total blood culture positivity was 38 (22.6\%) cases, and Enterococcus faecalis was the most common organism in this study.

Conclusion: The incidence and mortality of neonatal sepsis in LBW infants were still high. The importance of knowledge and awareness of pregnant women about danger signs and the risk of infection can reduce the incidence of early-onset neonatal sepsis. Prevention of healthcare-associated infections can reduce the incidence of lateonset neonatal sepsis.
'Department of Pediatrics, Faculty of Medicine, Universitas Udayana, Sanglah General Hospital, Bali, Indonesia
${ }^{*}$ Correspondence to:

Novita Purnamasari Assa; Department of Pediatrics, Faculty of Medicine, Universitas Udayana, Sanglah General Hospital, Bali, Indonesia;

dr.novita.assa@gmail.com

Received: 2019-06-11 Accepted: 2020-03-05 Published: 2020-03-19
Keywords: Characteristics, Neonatal Sepsis, Low Birth Weight

Cite This Article: Assa, N.P., Artana, I.W.D., Kardana, I.M., Putra, P.J., Sukmawati, M. 2020. The characteristics of neonatal sepsis in Low Birth Weight (LBW) infants at Sanglah General Hospital, Bali, Indonesia. Intisari Sains Medis 11(1): 172-178. D0I: 10.15562/ism.v11i1.522

\section{INTRODUCTION}

Neonatal sepsis is a clinical syndrome of systemic illness accompanied by bacteremia occurring in the first month of life. ${ }^{1,2}$ It is one of the significant causes of morbidity and mortality in neonates, especially in developing countries. According to the World Health Organization (WHO) in 2006, $26 \%$ of neonatal deaths occurred due to infection. ${ }^{3}$ The incidence of neonatal sepsis is approximately 1 to 10 cases per 1000 live births and 1 per 250 live premature births. Data from the Health Ministry of Republic of Indonesia's Fundamental Health Research (RISKESDAS) in 2007 revealed sepsis as the risk factor that causes neonatal death at the age of $0-6$ days $12 \%$ and $20.5 \%$ of neonatal mortality at 7-28 days. ${ }^{4}$

Several factors have been identified as the risk of neonatal sepsis. The microorganisms that cause sepsis will trigger a sepsis cascade that begins with the release of inflammatory sepsis mediators. The infection will be resisted by the body, both through the cellular immune system, which includes monocytes, macrophages, and neutrophils and through the humoral immunity system by forming antibodies and activating the complementary pathway. ${ }^{1,5,6}$ Newborn infants are less capable of responding to infection because of 1 or more immunologic deficiencies. Low birth weight 2.7 times more susceptible to sepsis due to less humoral and cellular immune systems, and the number of invasive diagnostic and therapeutic procedures performed. ${ }^{7}$

The clinical manifestations of newborn infections vary and include subclinical infection, mild to severe manifestations of focal or systemic infection, and, rarely, congenital syndromes resulting from in utero infection. The timing of exposure, inoculum size, immune status, and virulence of the aetiologic agent will influence the expression of disease. Because of the lack of specific symptoms that are associated with sepsis, and the limited laboratory criteria, diagnosis is difficult to enforce. Premature 
and VLBW newborns have improved survival but remain in the hospital for a long time in an environment that puts them at continuous risk for acquired infections. Based on those mentioned above, this study aims to describe the characteristics of neonatal sepsis in low birth weight infants in the neonatology intensive care unit of Sanglah Hospital.

\section{METHODS}

A retrospective observational cross-sectional study in subjects treated in the neonatology care unit of Sanglah Hospital from May 2017 - April 2018. The sample of the study is infants aged zero to 28 days with birth weights $<2,500$ grams with neonatal sepsis who were hospitalized in the level 2 and level 3 neonatology care rooms at Sanglah Hospital Denpasar during the study period. Exclusion criteria were incomplete medical record data, and babies go home at their request. The sampling technique is purposive sampling.

Variables assessed in this study were sex (male or female), location (Sanglah General Hospital or Referral) and mode (spontaneous, forceps extraction, vacuum extraction, or caesarean section) of delivery, birth weight $(<1,000$ gram, 1,000-1,499 gram, or 1,500-2,499 gram), gestational age ( $<28$ weeks, $28-31$ weeks, 32-36 weeks, or ${ }^{3} 37$ weeks), number of parity $(1,2$, or $>3)$, length of stay, onset of sepsis (EONS or LONS), as well as the outcome (survive or death). Data were analysed using SPSS version 17 for Windows. The result was presented in the descriptive form of narrative and tables are equipped with frequency display and presentation. Numerical data with normal distribution are shown in the median form (minimum-maximum) and data with abnormal distribution are presented in the mean form (standard deviation).

\section{RESULTS}

Diagnosis of sepsis in low birth weight (LBW) infants were 168 infants (49.7\%) with mortality $29.8 \%$. Most location of delivery at Sanglah Hospital (60.7\%). In this study showed male infants were more suffered from neonatal sepsis, approximately $53 \%$ cases than female $(47 \%)$. The most

\section{Table 1 Baseline characteristic of respondents and risk factors for neonatal sepsis}

\begin{tabular}{|c|c|c|}
\hline Variables & n (\%) & Mean \pm SD \\
\hline \multicolumn{3}{|l|}{ Sex } \\
\hline Male & $89(53)$ & \\
\hline Female & $79(47)$ & \\
\hline \multicolumn{3}{|l|}{ Location of delivery } \\
\hline Sanglah Hospital & $102(60.7)$ & \\
\hline Referral & $66(39.3)$ & \\
\hline \multicolumn{3}{|l|}{ Mode of delivery } \\
\hline Spontaneous & $86(51.2)$ & \\
\hline Forceps extraction & $1(0.6)$ & \\
\hline Vacuum extraction & $0(0)$ & \\
\hline Caesarian section & $81(48.2)$ & \\
\hline \multicolumn{3}{|l|}{ Birth weight } \\
\hline$<1,000$ gram & $27(16.1)$ & \\
\hline $1,000-1,499$ gram & $43(25.6)$ & \\
\hline $1,500-2,499$ gram & $98(58.3)$ & \\
\hline \multicolumn{3}{|l|}{ Gestational age } \\
\hline$<28$ weeks & $23(13.7)$ & \\
\hline 28-31 weeks & $49(29.2)$ & \\
\hline 32-36 weeks & $75(44.6)$ & \\
\hline$\geq 37$ weeks & $21(12.5)$ & \\
\hline \multicolumn{3}{|l|}{ Number of Parities } \\
\hline 1 & $77(45.9)$ & \\
\hline 2 & $42(25)$ & \\
\hline$\geq 3$ & $49(29.2)$ & \\
\hline
\end{tabular}


Table 1 Continue

\begin{tabular}{|c|c|c|}
\hline Variables & n (\%) & Mean \pm SD \\
\hline Length of Stay (LoS) (Days) & & $23.27 \pm 20.32$ \\
\hline \multicolumn{3}{|l|}{ Status of Sepsis } \\
\hline EONS & $164(97.8)$ & \\
\hline LONS & $4(2.4)$ & \\
\hline \multicolumn{3}{|l|}{ Outcome } \\
\hline Survive & $118(70.2)$ & \\
\hline Death & $50(29.8)$ & \\
\hline \multicolumn{3}{|l|}{ Major risk factor } \\
\hline PRM $>24$ hours & $25(14.9)$ & \\
\hline Maternal fever $>38^{\circ} \mathrm{C}$ & $8(4.8)$ & \\
\hline Chorioamnionitis & $2(1.2)$ & \\
\hline Fetal distress & $17(10.1)$ & \\
\hline Foul-smelling and or meconium-stained liquor & $14(8.3)$ & \\
\hline \multicolumn{3}{|l|}{ Minor risk factor } \\
\hline PRM $>12$ hours & $22(13.1)$ & \\
\hline Maternal fever $>37,5^{\circ} \mathrm{C}$ & $9(5.4)$ & \\
\hline Asphyxia & $69(41.1)$ & \\
\hline VLBW & $75(44.6)$ & \\
\hline Gestational age $<37$ weeks & $131(78)$ & \\
\hline Multiple gestations & $29(17.3)$ & \\
\hline Maternal vaginal discharge & $28(16.7)$ & \\
\hline Maternal urinary tract infection & $8(4.8)$ & \\
\hline
\end{tabular}

EONS: early-onset neonatal sepsis; LONS: late-onset neonatal sepsis

Table 2 Laboratorium evaluation and blood culture results of sepsis in low birth weight infants

\begin{tabular}{|c|c|c|c|}
\hline Parameters & n (\%) & Mean \pm SD & Median (Min-Max) \\
\hline \multicolumn{4}{|l|}{ Leucocyte $(\mathrm{K} / \mu \mathrm{L})$} \\
\hline$<5$ & $12(7.5)$ & & \\
\hline $5-34$ & $151(89.9)$ & & \\
\hline$>34$ & $5(3.1)$ & & \\
\hline Mean of Leucocyte $(\mathrm{K} / \mu \mathrm{L})$ & & $13.53 \pm 9.37$ & \\
\hline \multicolumn{4}{|l|}{ Neutrophil $(K / \mu \mathrm{L})$} \\
\hline$<1.5$ & $17(10.1)$ & & \\
\hline$>1.5$ & $151(89.9)$ & & \\
\hline Mean of Neutrophil $(K / \mu \mathrm{L})$ & & $6.87 \pm 6.66$ & \\
\hline \multicolumn{4}{|l|}{ IT Ratio } \\
\hline$\leq 0.2$ & $103(61.3)$ & & \\
\hline$>0.2$ & $65(38.7)$ & & \\
\hline IT ratio & & & $0.17(0.01-120.8)$ \\
\hline \multicolumn{4}{|l|}{ Platelets $(\mathrm{K} / \mu \mathrm{L})$} \\
\hline$<150$ & $52(31)$ & & \\
\hline$>150$ & $116(69)$ & & \\
\hline Mean of Platelets $(\mathrm{K} / \mu \mathrm{L})$ & & & $190.9(3.34-500.1)$ \\
\hline
\end{tabular}


Table 2 Continue

\begin{tabular}{|c|c|c|c|}
\hline Parameters & n (\%) & Mean \pm SD & Median (Min-Max) \\
\hline \multicolumn{4}{|l|}{ Procalcitonin (ng/mL) } \\
\hline$<0.05$ & $0(0)$ & & \\
\hline$>0.05$ & $120(100)$ & & \\
\hline Procalcitonin (ng/dL) & & $6.36 \pm 21.9$ & \\
\hline \multicolumn{4}{|l|}{ Peripheral blood smear } \\
\hline Vacuolization & $24(15.8)$ & & \\
\hline Toxic granule & $9(5.9)$ & & \\
\hline \multicolumn{4}{|l|}{ Gram-positive bacteria } \\
\hline Enterococcus faecalis & $10(6)$ & & \\
\hline Staphylococcus cohnii & $8(4.7)$ & & \\
\hline Staphylococcus haemolyticus & $6(3.5)$ & & \\
\hline Staphylococcus kloosin & $4(2.4)$ & & \\
\hline Staphylococcus epidermidis & $2(1.2)$ & & \\
\hline Staphylococcus coagulase negative & $1(0.6)$ & & \\
\hline \multicolumn{4}{|l|}{ Gram-negative bacteria } \\
\hline Pseudomonas aeroginosa & $2(1.2)$ & & \\
\hline Klebsiella pneumonia & $2(1.2)$ & & \\
\hline Acinetobacter baumannii & $1(0.6)$ & & \\
\hline Stenotrophomonas maltophilia & $1(0.6)$ & & \\
\hline Stephanoascus ciferrii & $1(0.6)$ & & \\
\hline Sterile & $130(77.4)$ & & \\
\hline
\end{tabular}

birth method was spontaneous birth (51.2\%) and caesarian section (48.2\%). The most subject birth weight were 1,500-2,499 grams (58.3\%) and the most gestational ages were $32-36$ weeks $(44,6 \%)$. Mean length of stay for patients LBW with neonatal sepsis was $23.27 \pm 20.32$ days. Early-onset neonatal sepsis (EONS) dominates patients with neonatal sepsis at Sanglah Hospital (97.6\%) and 4 infants (2.4\%) with late-onset neonatal sepsis (LONS). The characteristics of the sample are listed in Table 1.

In addition, Table 1 also showed that major infection risk factor of sepsis in LBW was premature rupture membrane (PRM) $>24$ hours (14.9\%), and minor infection risk factor was gestational age $<37$ weeks $(78 \%)$, very low birth weight $(44.6 \%)$ and asphyxia (41.1\%).

In Table 2, most of the patients showed normal leukocyte, neutrophils, platelet and IT ratio. From 168 LBW-sepsis infants, only 120 infants underwent procalcitonin examination. All of them showed elevated levels of procalcitonin. Peripheral blood smear in an infant with sepsis show vacuolization positive in $15.8 \%$ patient and toxic granule in $5.9 \%$ patient.

In Table 2, the study found that there were $38(22.6 \%)$ patients from $168 \mathrm{LBW}$-sepsis infants was obtained positive blood culture examination. Enterococcus faecalis was the most common organism in this study, then followed by Staphylococcus cohnii and Staphylococcus haemolyticus.

\section{DISCUSSION}

Neonatal sepsis is a clinical syndrome that arises due to a systemic inflammatory response that occurs as a result of bacterial, viral, fungal or parasitic infections that occur in the first 1 month of life. Data on the demographic characteristics of the subjects showed that most of them were male, approximately $53 \%$ cases than female infants $(47 \%)$. A predominance of a male infant is apparent in almost all studies of sepsis in the newborn infant but not among infants infected in utero. The usual male predominance in neonatal sepsis has suggested the possibility of a sex-linked factor in host susceptibility. A gene located in the X chromosome and involved with the function of the thymus or with a synthesis of immunoglobulins has been postulated. . $^{-11}$

In the LBW with sepsis, the mode of delivery that frequently seen was spontaneous delivery (51.2\%) and caesarian section $(48.2 \%)$. This frequency of mode delivery in low birth infants was similar to the previous study. ${ }^{12}$ The spontaneous delivery of LBW and premature infant usually is waited for some 
hours to make the maturity of the lung by giving glucocorticoid to the mother. Still, the other consequences are increasing the risk of infection from premature rupture of the membrane. The caesarian section may contribute to the changes of healthy flora in an infant. The normal flora in infants has a role in the immunity system of the infant so the changes in the normal flora normal may lead to a risk of sepsis condition. ${ }^{13}$

Several factors have been identified as the risk of neonatal sepsis. This study shows that major risk factor of sepsis in LBW was premature rupture membrane $(\mathrm{PRM})>24$ hours (14.9\%), and minor risk factor was gestational age $<37$ weeks $(78 \%)$, very low birth weight (44.6\%) and asphyxia (41.1\%). The presence of amniotic fluid contact with the extra-uterine environment through the occurrence of premature rupture of membranes increases the probability of ascending microorganism infection from the birth canal to the amniotic sac. ${ }^{14}$ Premature infants and LBW are risk factors for neonatal sepsis. Relative immunodeficiency, necessary medical interventions, i.e. antenatal corticosteroid, may be immunosuppressive and longer duration of stay that may lead to nosocomial infection. ${ }^{9,10}$ In the asphyxia condition, the LBW infant, was got the invasive procedure, i.e. resuscitation, intubation or prolonged of stay during stabilization. 15 This condition can increase the risk of infection, especially in LBW infants.

Neonatal sepsis is broadly categorized into early and late-onset sepsis depending upon the postnatal day of the presentation. Early-onset neonatal sepsis (EONS) occurs within the first 72 hours of life, while the late-onset neonatal sepsis (LONS) occurs after 72 hours. This classification is useful as a guide in antibiotic therapy concerning different transmission methods and causative organisms. ${ }^{2,3}$ Early-onset neonatal sepsis in this study was found in $97,6 \%$ subjects. Similar results were also found in several studies of previous neonatal sepsis. ${ }^{8,9,14}$ Early-onset neonatal sepsis is caused by vertical transmission of bacteria from mother to fetus during the antenatal and intranatal period, while LONS is associated with the horizontal transmission of postnatally acquired pathogens. This transmission can occur due to risk factors for infection and lack of knowledge and awareness of pregnant women about danger signs such as fever and premature rupture of membrane.

This study evaluated 6 infection markers in sepsis, namely leukocytes, neutrophils, platelets, IT ratio, procalcitonin, and blood smear. The infection markers in this study showed typical results in most subjects. This is thought to be related to the heterogeneity of the subject. Infection markers were taken when subjects were admitted to the hospital with cut-off results regardless of subject age. The infection markers listed are when the subject is admitted to the hospital considering the subject is mostly a referral case prior to the therapy has been obscured. Complete blood count (CBC) and differential may be ordered serially to determine changes associated with the infection (eg, thrombocytopenia or neutropenia) or to monitor the development of a left shift or changes in the ratio of immature to total neutrophils. Such serial monitoring of the CBC may be useful in aiding the differentiation of sepsis from nonspecific abnormalities due to the stress of delivery. ${ }^{16}$

The increase in circulating procalcitonin (PCT) concentration has been associated with neurotransmission, immunomodulation, and vascular control during infection and in the systemic inflammatory response syndrome (SIRS). Serum concentrations of PCT begin to rise four hours after exposure to bacterial endotoxin, peak at six to eight hours and remain raised for at least 24 hours. The half-life is estimated to be about 25-30 hours, and the serum concentrations do not appear to be affected by the gestational age. However, serum PCT concentrations vary widely in the first few days of life. The kinetics of PCT in non-infected newborns in the immediate postnatal period suggests that concentrations are relatively low soon after birth $(0.08 \mathrm{mg} /$ $\mathrm{ml})$, rise to a peak at $21-24$ hours $(0.6 \mathrm{ng} / \mathrm{ml})$, and return to the baseline by 48 hours of life. The reason for this "physiological" phenomenon is unknown but has been postulated to be the result of rapid colonization of bacteria in the gastrointestinal tract, followed by translocation of endotoxin through the bowel wall. Several studies have shown that serum PCT concentrations increase in systemic bacterial infection during early and late-onset neonatal infection. Its diagnostic profile has been claimed to be superior to other acute-phase proteins, including CRP, with sensitivity and specificity ranging from $87 \%$ to $100 \%$. In contrast, infants with a viral infection, bacterial colonization, and non-infected inflammatory stress, such as birth trauma, aspiration syndrome, and hypoxemia, have normal or only slightly raised concentrations. Further, definitively raised PCT concentrations in bacterial infection can be easily differentiated from the relatively small "physiological" increase in the immediate postnatal period. Unlike haematological indices, PCT has been reported to be useful in indicating the severity of infection, following the progress of treatment, and predicting outcomes. However, false-negative cases have also been found, and very high serum concentrations have been detected in patients with respiratory distress syndrome, acute lung and inhalation injuries, hemodynamic failure, and severe trauma, without bacterial infection. ${ }^{17}$ 
In this study, 120 patients from 168 patients with neonatal sepsis examined procalcitonin levels and obtained an increase in all patients with mean procalcitonin $6.52 \mathrm{ng} / \mathrm{mL}$ (SD 22.2).

Examination of blood culture is the gold standard in the diagnosis of sepsis in addition to several weaknesses, namely the length of the examination and the number of false-negative results. Positive results of blood culture depend on several factors, namely the technique of examination, microorganism density, previous antibiotic therapy, and sample volume. The absence of bacteria growth in the results of blood culture does not necessarily imply the absence of sepsis due to the low sensitivity of blood culture examination. The total blood culture positivity rate among low birth weight infants with sepsis in this study was 38 (22.6\%). The isolation rate of bacteria in this study is comparable to rates reported in Nepal (20.5\%) and Malaysia (26\%). ${ }^{18,19}$

Blood culture should be done in the presence of suspected sepsis. Still, some condition may interfere with this procedure such as financial problem, an antibiotic was already given, no media culture ready in the unit, and transportation of media culture to the microbiology. Gram positive organisms constituted the major group of isolates (81.58\%) from neonatal sepsis cases. Enterococcus faecalis was the most common organism in this study, then followed by Staphylococcus cohnii and Staphylococcus haemolyticus. Enterococci are gram-positive, catalase-negative, facultative anaerobes that grow as diplococci in short chains. Enterococci are normal flora of the gastrointestinal tract of humans and animals. They also may be found in oral secretions, the upper respiratory tract, skin, and the vagina. Enterococcus is currently recognized as one of the most common causes of nosocomial infections and is increasingly resistant to numerous antibiotics, including vancomycin. ${ }^{20,21}$ Staphylococcus cohnii and Staphylococcus haemolyticus, including Coagulase-negative staphylococci (CoNS) group. Due to the patient and procedure-related changes, CoNS now represent one of the major nosocomial pathogens, with S. epidermidis, S. cohnii, and S. haemolyticus being the most notable species. They account substantially for foreign body-related infections and infections in preterm newborns. ${ }^{22}$

There are 3 important things that can influence antibiotic selection: patient characteristics; risk factors for infection with specific pathogens; and the severity of the disease. Antibiotics should be started immediately after the infection is identified. The administration of single or combination antibiotics is still debated regarding the advantages and disadvantages. Antibiotic therapy in the NICU is usually empirical. Therefore, it is necessary to survey the pattern of antibiotic sensitivity to bacteria which is the dominant essential effort to monitor changes in patterns of sensitivity and provide guidance for clinicians in choosing appropriate empirical or definitive therapies, especially in NICU. Prevention of healthcare-associated infections through antimicrobial stewardship, limited steroid use, early enteral feeding, limited use of invasive devices and standardization of catheter care practices, and meticulous hand hygiene are important and cost-effective strategies for reducing the burden of late-onset neonatal sepsis. ${ }^{23,24}$

This study has several limitations. This study uses a retrospective descriptive method so that it cannot assess the significance of the results of the study. The study also did not identify patterns of antibiotic sensitivity and resistance which could also play a role in the outcome of neonatal sepsis. The infection markers listed in this study are when the subject is admitted to the hospital. At the same time, the time is not necessarily the beginning of the appearance of symptoms considering that most of the subjects are referral cases that have been treated in other hospitals that may be in therapy so that the marker of infection cannot actual sepsis condition..

\section{CONCLUSION}

Premature infants and LBW are risk factors for neonatal sepsis. The incidence and mortality of neonatal sepsis in LBW infants were still high. The importance of knowledge and awareness of pregnant women about danger signs and the risk of infection can reduce the incidence of early-onset neonatal sepsis. Prevention of associated healthcare infections can reduce the incidence of late-onset neonatal sepsis.

\section{CONFLICT OF INTEREST}

None

\section{ETHICS CONSIDERATION}

Ethics approval has been obtained prior to the study being conducted from the Ethics Committee, Faculty of Medicine, Universitas Udayana, Bali, Indonesia prior to the study being conducted.

\section{FUNDING}

None

\section{AUTHOR CONTRIBUTION}

All of the authors are equally contribute to the study from the conceptual framework, data gathering, data analysis, until interpreting the results of study. 


\section{REFERENCES}

1. Evina B. Clinical Manifestations and Diagnostic Criteria of Atopic Dermatitis. J Majority. 2015;4(4):23-29.

2. Gomella TL. Sepsis. In: Gomella TL, Cunningham MD, Eyal FG, editors. Neonatology management, prosedures, on-call problems, disease, and drugs. Seventh Edition. New York: McGraw Hill; 2013. p, 865-73.

3. Aminullah A. Sepsis pada bayi baru lahir. In: Kosim M, Yunanto A, Dewi R, Saroso GI, Usman A, editors. Buku Ajar Neonatologi. $1^{\text {st }}$ edition. Jakarta: Badan Penerbit IDAI; 2008. p, 170-87.

4. World Health Organization. Neonatal and perinatal mortality: country, regional and global estimates. World Health Organization; 2006. p, 1-75.

5. Ministry of Health. Report on Result of National Basic Health Research (RISKESDAS) 2007. Jakarta: The National of Health Research and Development Ministry of Health of the Republic of Indonesia; 2008.

6. Short MA. Linking the sepsis triad of inflammation, coagulation and suppressed fibrinolysis to infants. Adv Neonat Care. 2004;4(5):258-73.

7. Bone RC. A Continuing evolution in our understanding of the systemic inflammatory response syndromes (SIRS) and the multiple organ dysfunction syndromes (MODS). Ann Intern Med. 1996;125(8):680-7.

8. Makhoul IR, Sujov P, Smolkin T, Lusky A, Reichman B, Israel Neonatal Network. Pathogen-specific early mortality in very low birth weight infants with late-onset sepsis: a national survey. Clinical Infectious Diseases, 2005;40(2):218-24.

9. Jain NK, Jain VM, Maheshwari S. Clinical profile of neonatal sepsis. Kathmandu Univ Med J (KUMJ). 2003;1(2):117-20.

10. Washburn T, Medearis DN Jr, Childs B. Sex differences insusceptibility to infections. Pediatrics. 1985; 35:57-60.

11. Purtillo DT, Sullivan JL. Immunological basis for superior survival of females. Am J Dis Child. 1979; 133(12):1251-3.

12. Simiyu E. Morbidity and mortality of the low birth weight infants in newborn unit in Kenyatta National Hospital, Nairobi. East African Med J. 2004;81(7):367-74.

13. Sung NJ, Lee SG, Kim MJ, Kim YH, Yang S, Hwang IT, et al. The changes of Intestinal normal flora in neonates for seven days postnatally. Korean J Pediatr Gastroenterol Nutr. 2006;9(2):162-8.
14. Jiang Y, Kuang L, Wang H, Li L, Zhou W, Li M. The Clinical Characteristics of Neonatal Sepsis Infection in Southwest China. Intern Med. 2016;55(6):597-603.

15. Ringer S. Care of the extremley low birth weight infant. In: Cloherty J, Eichenwald EC, Stark AR, editor. Manual of neonatal care. Philadelphia: Lippincott Williams \& Wilkins; 2008. p.78-85.

16. Gerdes JS. Clinicopathologic approach to the diagnosis of neonatal sepsis. Clin Perinatol. 1991;18(2):361-81.

17. Chiesa C, Panero A, Osborn JF, Simonetti AF, Pacifico L. Diagnosis of Neonatal Sepsis: A Clinical and Laboratory Challenge. Clin Chem. 2004;50(2):279-287.

18. Awaisu A, Sulaiman SAS, Ibrahim MIM, Saad A. Antimicrobials utilization and outcomes of neonatal sepsis among patients admitted to a University Teaching Hospital in Malaysia. Eastern Journal of Medicine. 2007;12(1):6-14.

19. Akhter RJ, Hoque MM, Yasmeen BHN, Chowdhury MAKA. Bacteriological profile and sensitivity pattern of neonatal sepsis. Northern International Medical College Journal. 2016;8(1):174-7.

20. Morrison D, Woodford N, Cookson B. Enterococci as emerging pathogens of humans. Soc Appl Bacteriol Symp Ser. 1997;26:89S-99S.

21. Hufnagel M, Liese C, Loescher C, Kunze M, Proempeler H, Berner R, et al. Enterococcal colonization of infants in a neonatal intensive care unit: associated predictors, risk factors and seasonal patterns. BMC Infect Dis. 2007;7:107.

22. Becker K, Heilmann C, Peters G. Coagulase-Negative Staphylococci. Clin Microbiol Rev. 2014;27(4):870-926

23. Karam G, Chastre J, Wilcox MH, Vincent JL. Antibiotic strategies in the era of multidrug resistance. Crit Care. 2016;20(1):136.

24. Vincent JL, Bassetti M, François B, Karam G, Chastre J, Torres A, et al. Advances in antibiotic therapy in the critically ill. Crit Care. 2016;20(1):133.

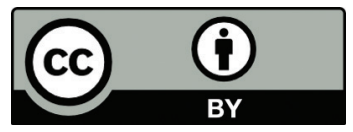

This work is licensed under a Creative Commons Attribution 